\title{
Evaluation of Hydraulic Performance of Dripper Installed in Drip Irrigation System
}

\author{
Aditi Deepak and Sudarshan Prasad* \\ College of Agricultural Engineering, Dr. Rajendra Prasad Central Agricultural University, \\ Pusa (Bihar), India \\ *Corresponding author
}

\section{A B S T R A C T}

The experiment has been conducted to evaluate the hydraulic performance of the drippers fitted with drip irrigation system at experimental field of College of Agricultural Engineering under Dr. Rajendra Prasad Central Agricultural University, Pusa in

\section{Keywords}

Hydraulic performance, Dripper, Drip irrigation system

Article Info

Accepted:

26 May 2020

Available Online:

10 June 2020 Samastipur district (Bihar), India. The drip irrigation system installed in the field was divided in two parts i.e. left-side and right-side of the sub-main pipeline. Each side has 32 beds of turmeric crop with total number of 64 beds each having a set of two laterals. Each lateral of size $16.0 \mathrm{~mm}$ was fitted with 38 number of in-line drippers of inner diameter $13.2 \mathrm{~mm}$ and rated discharge capacity of 4.01ph. In present study, four laterals on two beds each side were selected at upper end, middle part and tail end along the sub-main for evaluation of its performance. Results indicated the linearly increasing cumulative pressure head loss along tail end of each lateral. High values of degree of agreement i.e.0.87 between the measured and the estimated dripper's discharge at mean exponent value of 0.31 and coefficient value of (1.48) in discharge-pressure head relationship with power function for drippers installed with the system was observed. The mean statistics of Chi-square test and root mean square error (RMSE) were found to be lowest i.e. 0.13 and 0.07 for left-side drippers and 0.27 and 0.10 for right-side drippers of the sub-main pipeline.

\section{Introduction}

Agriculture is the biggest source of livelihoods in India where 70 percent of its rural households including 82 percent of farmers being small and marginal, depend primarily on agriculture for their survival. Agriculture, particularly in Bihar, is the vital source of income for majority of people where about $83 \%$ of total land holdings belong to marginal farmers, $10 \%$ to small farmers and $7 \%$ to those farmers whose land holdings are more than 2 ha. Further, about 75 $\%$ of the global freshwater is used for irrigation of agricultural crops. In the changing scenario of climate, survival of farmers due to diminishing trend of water resource has become a great challenge. Moreover, the wastages of water occurring through storage, conveyance and distribution ultimately result in delivering 30 to $35 \%$ of stored water for plant uptake because most of 
the water is applied to the field by conventional surface methods of irrigation. The traditional flood or ridge and furrow method of irrigating field suffers with various problems such as considerable seepage, conveyance and evaporation loss; higher energy cost; lower water productivity; leaching of costly agricultural inputs causing sub-surface water pollution.

In drip irrigation method, irrigation water is applied directly to the crop root zone uniformly in agricultural fields. Drippers are the main device which is used to dissipate the pressure of irrigation water flowing through the lateral and to discharge a little flow at a constant rate at various emitting points along a lateral. Celik et al., (2015) stated in his study that the drippers are designed in such a way that the individual discharge does not vary significantly throughout the lateral length with minor changes in pressure. To establish a hydraulic balance to achieve uniform discharge of drippers and to ensure uniform application of irrigation water over the field, a properly designed drip irrigation system is essential to get high irrigation efficiency. The flow rate of drippers is a function of pressure head available at emitting point. Hezarjaribi (2008) stated that all drippers in the system should discharge equal amounts of water, but due to manufacturing variations, pressure variation due to friction and other minor fittings throughout the length of lateral, drippers aging, its sensitivity to pressure and change in temperature of irrigation water, the variation in flow rates between two supposedly identical drippers exist (Mizyed and Kruse, 2008). Badr et al., (2009) mentioned that the pressure head along lateral line is greatly affected by the friction head loss and elevation head. As dripper discharge is related to pressure head along the lateral, the pressure variation changes the water flow from drippers along the line. Keller and Karmeli (1974) and Howell and
Barinas (1980) used the dripper's exponent in the relationship of discharge and pressure head to study the characteristics of dripper's flow regime and suggested to use to characterise the hydraulics performance of a dripper.

Bortolini and Frisco (2017) carried out indoor laboratory tests to determine the accuracy with which the discharge coefficient $(K)$ and the emitter discharge exponent $(x)$, and the number of significant digits to be reported. They compared the two calculation methods to obtain $K$ and $x$ : the method of measurements and the data regression analysis. The results showed that, due to a calculation error of $15 \%$, the maximum precision of the $C V$ obtained in this analysis allowed the use of only one decimal of significant digits. As regards $K$ and $x$, the method of the two measurements showed high levels of uncertainty ( $9 \%$ for $K$ and 3.6 $\%$ for $x$, respectively) despite the accuracy of the measurements; therefore, they indicated only two significant decimal digits for $x$ and no decimals for $K$. Kirnak et al., (2004) compared the manufacturers reported discharge rates and coefficients of manufacturing variation values with test results for various types of in-line emitters manufactured by four different companies in Turkey. They tested a total of nine drip irrigation lines, comprising 7 noncompensating and 2 compensating emitters, at $50,100,150,200$ and $250 \mathrm{kPa}$ pressures. They found that the compensating emitter exponents ranged from 0.02 to 0.05 while non-compensating emitters values varied between 0.60 and 0.85 . They showed that only 1 of the 7 non-compensating emitters and both compensating emitters had flow rates within $\pm 10 \%$ of manufacturers reported values. They carried out the t-test analysis between manufacturers reported and measured mean flow rates at manufacturers reported nominal operating heads and found that there was no significant statistical 
difference at less than 0.05 level.

Keeping above in view and the factors like inlet pressure, head loss due to friction and insertion of drippers inside the laterals, flow variation, average flow rate through drippers etc. which are useful information while designing the system and making the recommendation on irrigation scheduling, the hydraulic evaluation dripper of performance installed on laterals in drip irrigation system became necessary and undertaken.

\section{Materials and Methods}

\section{Experimental site and climatic condition}

The experimental site is located in the premise of College of Agricultural Engineering, Dr. Rajendra Prasad Central Agricultural University, Pusa. The site is located in Samastipur district of North Bihar (India) at $25^{\circ} 98^{\prime} \mathrm{N}$ latitude and $85^{\circ} 65^{\prime} \mathrm{E}$ longitude at an elevation of $52.00 \mathrm{~m}$ above sea level. Whether in the region become coldest in the month of January in which the minimum goes down to approximately $4^{\circ} \mathrm{C}$ and hottest in May and June in which maximum rises up to $42^{\circ} \mathrm{C}$. whereas, the humidity was observed in the range of minimum $34 \%$ in the month of January and maximum $98 \%$ in the months of September and October. The region receives the annual rainfall of $1034.4 \mathrm{~mm}$ (in the year 2019) out of which around $92.2 \%(959.1 \mathrm{~mm})$ occurs in the monsoon season i.e. the months of June, July, August and September.

\section{Pressure and discharge measurement}

Pressure at head and tail ends of each laterals selected at upper end, middle part and tail end of the sub-main was recorded with the help of pressure gauge. The water discharged through each in-line dripper and discharge of each lateral under the study was measured in a container kept beneath it, using volumetric measurement. The drip system was operated for 5 minutes and volume of water collected in the containers was measured with the help of graduated cylindrical.

\section{Determination of head loss}

The head losses in drip laterals can be determined by estimating the head losses due to friction and insertion of dripper along the drip laterals (Celik et al., 2015) which can be described as follows:

\section{Determination of Head Loss due to Friction}

The head loss $\left(\mathrm{h}_{\mathrm{f} f}\right)$ due to friction between the internal surface of the lateral and the flowing water was determined by Darcy-Weisbach equation (Giles et al., 1995 and Celik et al., 2015) which can be written as:

$$
h_{f f}=f \frac{L V^{2}}{2 g d}
$$

Where, $f$ is the friction factor, $\mathrm{L}$ is the length of pipe or lateral $(\mathrm{m}), d$ is the internal diameter of pipe orlateral $(\mathrm{m}), \mathrm{v}$ is the velocity of flow through the pipe or lateral $(\mathrm{m} / \mathrm{s})$ and $g$ is the gravitational constant $\left(\mathrm{m} / \mathrm{s}^{2}\right)$. For smooth pipe, the friction factor $(f)$ is characterised using Reynold's number $\left(R_{e}\right)$ as follows :

$$
\begin{array}{cr}
f=\frac{R_{e}}{64}, & \text { if } R_{e} \leq 2000 \\
f= & 0.32 R_{e}{ }^{-0.25},
\end{array}
$$

Where, ${ }^{v}$ is kinematic viscosity of water $(1 \times$ $10^{-6} \mathrm{~m}^{2} / \mathrm{sec}$, at $20^{\circ} \mathrm{C}$ temperature of flowing water). 


\section{Determination of head loss due to insertion}

Provenzano and Pumo (2004) suggested equation was used to determine head loss due to the insertion $\left(\boldsymbol{h}_{f e}\right)$ of in-line drippers in lateral which can be described as follows :

$$
h_{f e}=\beta \frac{V^{2}}{2 g}
$$

Where, $\beta$ is the constant and can be determined by using :

$$
\beta=0.056\left[\left(\frac{d_{i}}{d_{g}}\right)^{17.83}-1\right]
$$

Where, $d_{i}$ is the internal diameter of lateral, $\mathrm{mm}$ and $d_{g}$ is internal diameter due to dripper, $\mathrm{mm}$.

\section{Determination of pressure head available at emitting point}

Empirical model was developed to compute the pressure head available at each emitting point $\left(\mathrm{H}_{\mathrm{i}}\right)$ at which dripper discharges water to the plant's root can be determined by using the generalised equation mentioned below:

$$
H_{i}=H-h_{f f_{0}}-(i-1)\left(h_{f f}+h_{f \theta}\right)-h_{s}
$$

Where, $\mathrm{H}_{\mathrm{i}}$ is the pressure head available at $\mathrm{i}^{\text {th }}$ dripper (m), $h_{f f o}$ is the head loss due to friction in lateral pipe between outlet at submain and $1^{\text {st }}$ dripper $(\mathrm{m})$. If spacing between the drippers is equal to the distance between outlet at sub-main and $1^{\text {st }}$ dripper, then $h_{f f o}=h_{f f}$ else, $h_{f f}$ is the head loss due to friction in lateral pipe between drippers (m), $h_{f e}$ is the head loss due to insertion of in-line dripper in lateral pipe (m), and $h_{s}$ is the gain or loss in pressure head due to down or up slope of the ground surface along the lateral, respectively. Here, $h_{s}=0$ for levelled surface was taken.

\section{Pressure-discharge relationship}

The empirical relationship between the pressure head available at each emitting points and the discharge of an in-line dripper was developed as follow:

$$
q_{i}=K H_{i}^{x}
$$

Where, $q_{i}$ is the discharge of $\mathrm{i}^{\text {th }}$ dripper (lph). $\mathrm{K}$ is the constant and $\mathrm{x}$ is exponent which varies between 0 and 1. Emission device may be classified as pressure compensating type with variable flow path if the value of $x$ ranges from 0 to 0.3 ; vortex type with vertex flow regime if the value of $x$ equals to 0.4 ; orifice type with fully turbulent flow if the value of $x$ equals to 0.5 ; long or spiral path with mostly turbulent flow if the value of $x$ lies between 0.6 to 0.8 ; micro tube with mostly laminar flow if the value of $x$ equals to 0.9 ; and capillary type with fully laminar flow if the value of $\mathrm{x}$ equals to 1.0 (www.agridrip.com/page/437645582).

\section{Flow variation of dripper}

The variation of dripper's discharge was used to judge for whether the flow variations is acceptable or unacceptable and was mathematically, can be written as:

$$
q_{\text {var }}=\frac{q_{\max }-q_{\min }}{q_{\max }} \times 100
$$

Where, ${ }^{q}$ var is the variation in dripper's flow rate $(\%),{ }^{q_{\max }}$ is the maximum dripper's flow rate (lph), and $q_{\min }$ is the minimum value of dripper's flow rate (lph). The desirable value 
is less than $10 \%$, acceptable value lies between 10 to $20 \%$, and unacceptable value is greater than $20 \%$.

\section{Statistical analysis}

Following statistical parameters were used to test the closeness between measured and estimated dripper's discharge using selected exponent and coefficient in dischargepressure relationship developed for dripper.

\section{Degree of agreement (d)}

The Willmott index of agreement $(d)$ was used as a relative measure of the difference between the variables and is written as (Prasad et. al. 2013; Zhou and Zhou, 2009 and Lopez-Urera et al., 2006):

$$
d=1-\frac{\sum\left(D_{m}-D_{E}\right)^{2}}{\Sigma\left[\left(D_{m}-D_{m}\right)+\left(D_{e}-D_{e}\right)\right]^{2}}
$$

\section{Root Mean Square Error (RMSE)}

RMSE was used to measure the average magnitude of the errors between the measured and the estimated dripper's discharge installed in the system. RMSE value of zero is considered as perfect match.

RMSE $=\sqrt{\frac{\sum\left(D_{m}-D_{E}\right)^{2}}{N}}$

Chi-Square $\left(\chi^{2}\right)$ :This test was used to evaluate the closeness between measured and estimated dripper's discharge and can be expressed as follows :

$$
\chi^{2}=\sqrt{\frac{\sum\left(D_{m}-D_{E}\right)^{2}}{D_{E}}}
$$

Where, ${ }^{D_{m}}$ and ${ }^{D_{E}}$ are the measured and estimated flow rate of drippers installed along the lateral and $\mathrm{N}$ is the number of drippers along a lateral.

\section{Results and Discussion}

The drip irrigation system was installed on total area of 1000 square meter with lateral to lateral spacing of $40 \mathrm{~cm}$ and dripper to dripper spacing of $30 \mathrm{~cm}$. The sub-main pipeline of the system separates the whole field in two parts i.e. left side and right side of the sub-main. Each side has 32 beds of turmeric crop with total of 64 beds each having a set of two laterals. The total no. of 128 laterals of size $16.0 \mathrm{~mm}$ were spread over the field. Each lateral was fitted with 38 number of in-line drippers of inner diameter $13.2 \mathrm{~mm}$ and rated discharge capacity of 4 lph. In present study, four laterals on two beds were selected from both sides i.e. left side and right side of the sub-main at upper end, middle part and tail end along the sub-main for evaluation of its performance. Discharge and pressure of selected laterals along the sub-main were measured using volumetric measurent and pressure gauge, respectively and presented in Table 1. Table (1) indicated that the pressure head varies from $2.0 \mathrm{~m}(0.20$ $\left.\mathrm{kg} / \mathrm{cm}^{2}\right)$ at tail end to $2.6 \mathrm{~m}\left(0.26 \mathrm{~kg} / \mathrm{cm}^{2}\right)$ at upper end of the sub-main while the flow velocity of water in the laterals ranges from $0.71 \mathrm{~m} / \mathrm{sec}$ to $0.75 \mathrm{~m} / \mathrm{sec}$. The water flow rate in the lateral was found to be fluctuating between $461.54 \mathrm{lph}$ and $580.65 \mathrm{lph}$ with mean flow rate of $525 \mathrm{lph}$ in each lateral installed over the field (Table 1).

Containers were placed below each dripper installed along the laterals (both side i.e. right side and left side of sub-main) and volumetric measurement was carried out to determine the water flow rate through each dripper. Thus, the mean flow rate of each dripper fitted with laterals was found to be $1.74 \mathrm{lph}$ against rated flow rate of $4.00 \mathrm{lph}$. Pressure head losses due to friction and due to insertion of drippers in 
lateral were determined using equation nos. (1) and (5), and the cumulative head loss along the tail end of the laterals fitted on leftside and right-side of the sub-main were presented in Figs. (1) and (2), respectively. The figures clearly showed that the cumulative pressure head loss was observed to be linearly increasing along the tail end of the laterals.

The pressure head available at each emitting device fitted with laterals was estimated by using equation no. (7). The graph between the measured discharge of drippers against the pressure head available at each dripper installed along the laterals laid out left-side and right-side of sub-main were plotted and shown in Fig. (3) and (4), respectively.
The variation in dripper's flow rates can be clearly seen in the figures. The increasing discharge with increasing pressure head available was observed to be closely related with power function of pressure heads available at each emitting device. The values of exponent and the coefficient in dischargepressure equation no. (8) were determined to be 0.295 and 1.523 for the drippers installed on laterals left-side of the sub-main (Fig. 3) and 0.260 and 1.526 for the drippers installed on laterals right-side of the sub-main (Fig. 4). The high correlation coefficients between the dripper's discharge and the pressure head available at each dripper was observed to be $90.91 \%$ and $84.26 \%$ for the drippers installed on laterals left-side and right-side of sub-main, respectively (Figs. 3 and 4; Table 2 and 3).

Table.1 Hydraulic parameters of selected laterals of drip irrigation system installed at the site under study

\begin{tabular}{|l|c|c|c|c|c|c|}
\hline Position of lateral & \multicolumn{3}{|c|}{ Left side of sub-main } & \multicolumn{3}{|c|}{ Right side of sub-main } \\
\cline { 2 - 6 } & $\begin{array}{c}\text { Head } \\
\text { (m) }\end{array}$ & $\begin{array}{c}\text { Discharge } \\
\text { (lph) }\end{array}$ & $\begin{array}{c}\text { Flow } \\
\text { velocity } \\
\text { (m/sec) }\end{array}$ & $\begin{array}{c}\text { Head } \\
\text { (m) }\end{array}$ & $\begin{array}{c}\text { Discharge } \\
\text { (lph) }\end{array}$ & $\begin{array}{c}\text { Flow } \\
\text { velocity } \\
\text { (m/sec) }\end{array}$ \\
\hline Upper-end lateral-1 & 2.50 & 545.45 & 0.75 & 2.60 & 545.45 & 0.75 \\
\hline Upper-end lateral-2 & 2.50 & 529.41 & 0.73 & 2.50 & 514.29 & 0.71 \\
\hline Upper-end lateral-3 & 2.40 & 514.29 & 0.71 & 2.50 & 514.29 & 0.71 \\
\hline Upper-end lateral-4 & 2.30 & 562.50 & 0.78 & 2.30 & 500.00 & 0.69 \\
\hline $\begin{array}{l}\text { Middle-part } \\
\text { lateral-1 }\end{array}$ & 2.40 & 545.45 & 0.75 & 2.30 & 514.29 & 0.71 \\
\hline $\begin{array}{l}\text { Middle-part } \\
\text { lateral-2 }\end{array}$ & 2.10 & 529.41 & 0.73 & 2.40 & 545.45 & 0.75 \\
\hline $\begin{array}{l}\text { Middle-part } \\
\text { lateral-3 }\end{array}$ & 2.40 & 514.29 & 0.71 & 2.30 & 473.68 & 0.65 \\
\hline $\begin{array}{l}\text { Middle-part } \\
\text { lateral-4 }\end{array}$ & 2.30 & 580.65 & 0.80 & 2.20 & 461.54 & 0.64 \\
\hline Lower-end lateral-1 & 2.20 & 529.41 & 0.73 & 2.40 & 529.41 & 0.73 \\
\hline Lower-end lateral-2 & 2.30 & 514.29 & 0.71 & 2.30 & 514.29 & 0.71 \\
\hline Lower-end lateral-3 & 2.30 & 529.41 & 0.73 & 2.40 & 526.32 & 0.73 \\
\hline Lower-end lateral-4 & 2.00 & 524.78 & 0.73 & 2.10 & 526.32 & 0.73 \\
\hline & & & & & & \\
\hline
\end{tabular}


Table.2 Hydraulic parameters of selected laterals of drip irrigation system installed at the site under study

\begin{tabular}{|l|c|c|c|c|c|c|}
\hline \multirow{2}{*}{ Position of lateral } & \multicolumn{3}{|c|}{ Left side of sub-main } & \multicolumn{3}{c|}{ Right side of sub-main } \\
\cline { 2 - 7 } & $\mathbf{x}$ & $\mathbf{K}$ & $\begin{array}{c}\text { Flow } \\
\text { variation (\%) }\end{array}$ & $\mathbf{x}$ & $\mathbf{K}$ & $\begin{array}{c}\text { Flow } \\
\text { variation (\%) }\end{array}$ \\
\hline Upper-end lateral-1 & 0.28 & 1.48 & 20.37 & 0.18 & 1.58 & 20.79 \\
\hline Upper-end lateral-2 & 0.17 & 1.66 & 12.35 & 0.60 & 1.25 & 21.70 \\
\hline Upper-end lateral-3 & 0.37 & 1.44 & 24.12 & 0.31 & 1.32 & 24.70 \\
\hline Upper-end lateral-4 & 0.13 & 1.63 & 12.50 & 0.19 & 1.39 & 21.57 \\
\hline Middle-part lateral-1 & 0.25 & 1.53 & 19.00 & 0.31 & 1.56 & 20.30 \\
\hline Middle-part lateral-2 & 0.31 & 1.53 & 18.60 & 0.47 & 1.33 & 19.40 \\
\hline Middle-part lateral-3 & 0.23 & 1.49 & 20.81 & 0.18 & 1.39 & 12.03 \\
\hline Middle-part lateral-4 & 0.36 & 1.45 & 21.40 & 0.19 & 1.49 & 14.67 \\
\hline Lower-end lateral-1 & 0.33 & 1.51 & 27.27 & 0.34 & 1.35 & 19.50 \\
\hline Lower-end lateral-2 & 0.29 & 1.52 & 21.25 & 0.31 & 1.49 & 21.74 \\
\hline Lower-end lateral-3 & 0.32 & 1.55 & 24.70 & 0.28 & 1.52 & 22.75 \\
\hline Lower-end lateral-4 & 0.30 & 1.60 & 27.27 & 0.18 & 1.41 & 21.88 \\
\hline Mean & $\mathbf{0 . 2 8}$ & $\mathbf{1 . 5 3}$ & $\mathbf{2 2 . 7 6}$ & $\mathbf{0 . 3 0}$ & $\mathbf{1 . 4 2}$ & $\mathbf{2 3 . 6 4}$ \\
\hline
\end{tabular}

Table.3 Statistical parameters between measured and estimated dripper's discharge (at $\mathrm{x}=0.31$ and $\mathrm{K}=1.48$ ) installed on laterals in drip irrigation system

\begin{tabular}{|c|c|c|c|c|c|c|}
\hline \multirow{2}{*}{ Position of lateral } & \multicolumn{3}{|c|}{ Left side of sub-main } & \multicolumn{3}{c|}{ Right side of sub-main } \\
\cline { 2 - 7 } & $\mathbf{d}$ & $\boldsymbol{\chi}^{\mathbf{2}}$ & $\mathbf{R M S E}$ & $\mathbf{d}$ & $\boldsymbol{\chi}^{\mathbf{2}}$ & RMSE \\
\hline Upper-end lateral-1 & 0.95 & 0.06 & 0.06 & 0.78 & 0.28 & 0.12 \\
\hline Upper-end lateral-2 & 0.83 & 0.15 & 0.08 & 0.74 & 0.77 & 0.20 \\
\hline Upper-end lateral-3 & 0.99 & 0.01 & 0.03 & 0.99 & 0.01 & 0.03 \\
\hline Upper-end lateral-4 & 0.77 & 0.28 & 0.11 & 0.78 & 0.23 & 0.10 \\
\hline Middle-part lateral-1 & 0.98 & 0.03 & 0.04 & 0.91 & 0.20 & 0.09 \\
\hline Middle-part lateral-2 & 0.94 & 0.12 & 0.07 & 0.97 & 0.05 & 0.05 \\
\hline Middle-part lateral-3 & 0.94 & 0.09 & 0.06 & 0.60 & 0.89 & 0.20 \\
\hline Middle-part lateral-4 & 0.97 & 0.07 & 0.05 & 0.49 & 0.27 & 0.11 \\
\hline Lower-end lateral-1 & 0.97 & 0.07 & 0.06 & 0.74 & 0.39 & 0.14 \\
\hline Lower-end lateral-2 & 0.93 & 0.08 & 0.06 & 0.99 & 0.02 & 0.03 \\
\hline Lower-end lateral-3 & 0.88 & 0.20 & 0.09 & 0.95 & 0.07 & 0.06 \\
\hline Lower-end lateral-4 & 0.83 & 0.38 & 0.12 & 0.92 & 0.11 & 0.07 \\
\hline Mean & $\mathbf{0 . 9 1}$ & $\mathbf{0 . 1 3}$ & $\mathbf{0 . 0 7}$ & $\mathbf{0 . 8 2}$ & $\mathbf{0 . 2 7}$ & $\mathbf{0 . 1 0}$ \\
\hline
\end{tabular}




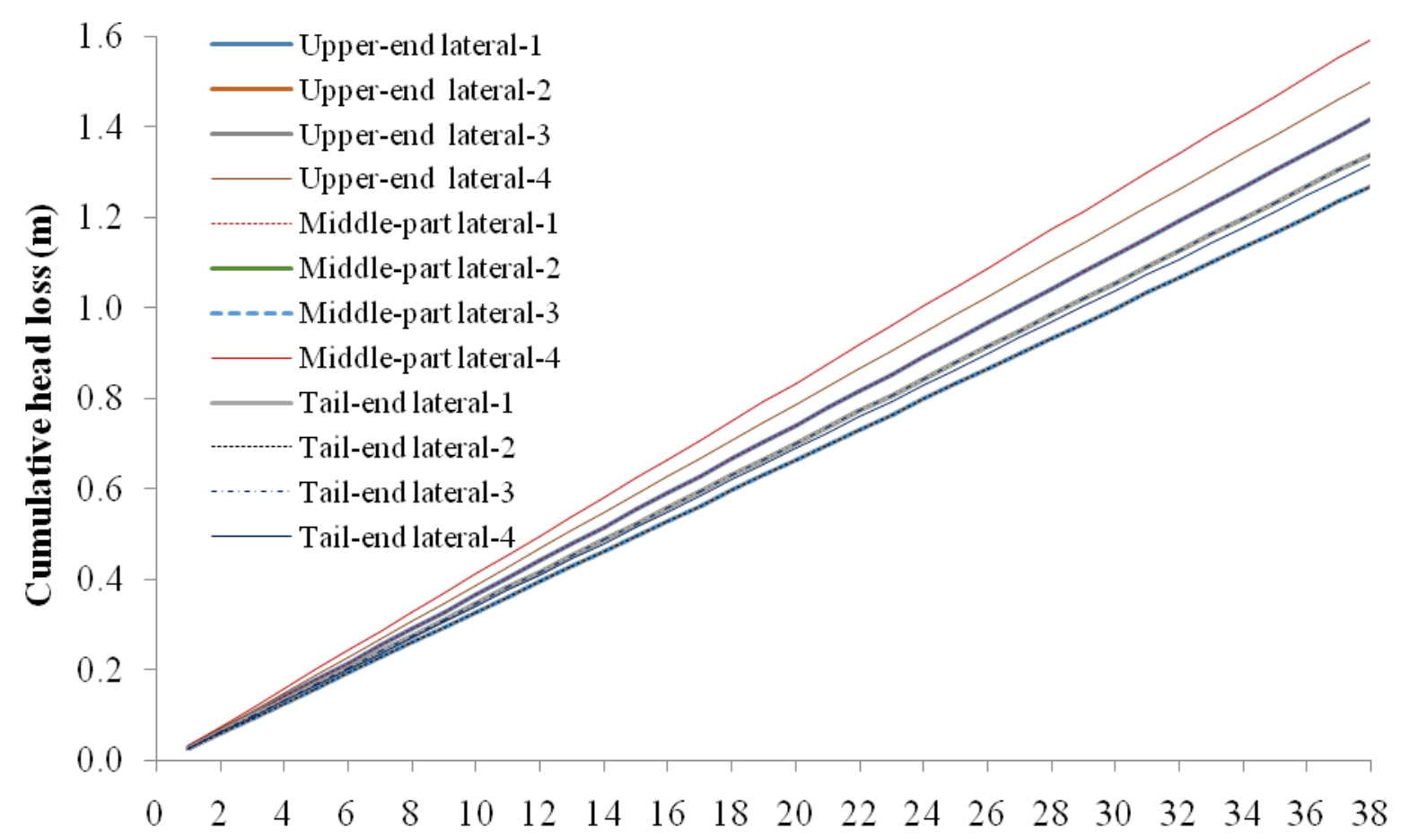

Position of drippers along lateral

Fig.1 Cumulative pressure head loss in the direction of flow along the lateral installed on leftside of sub-main

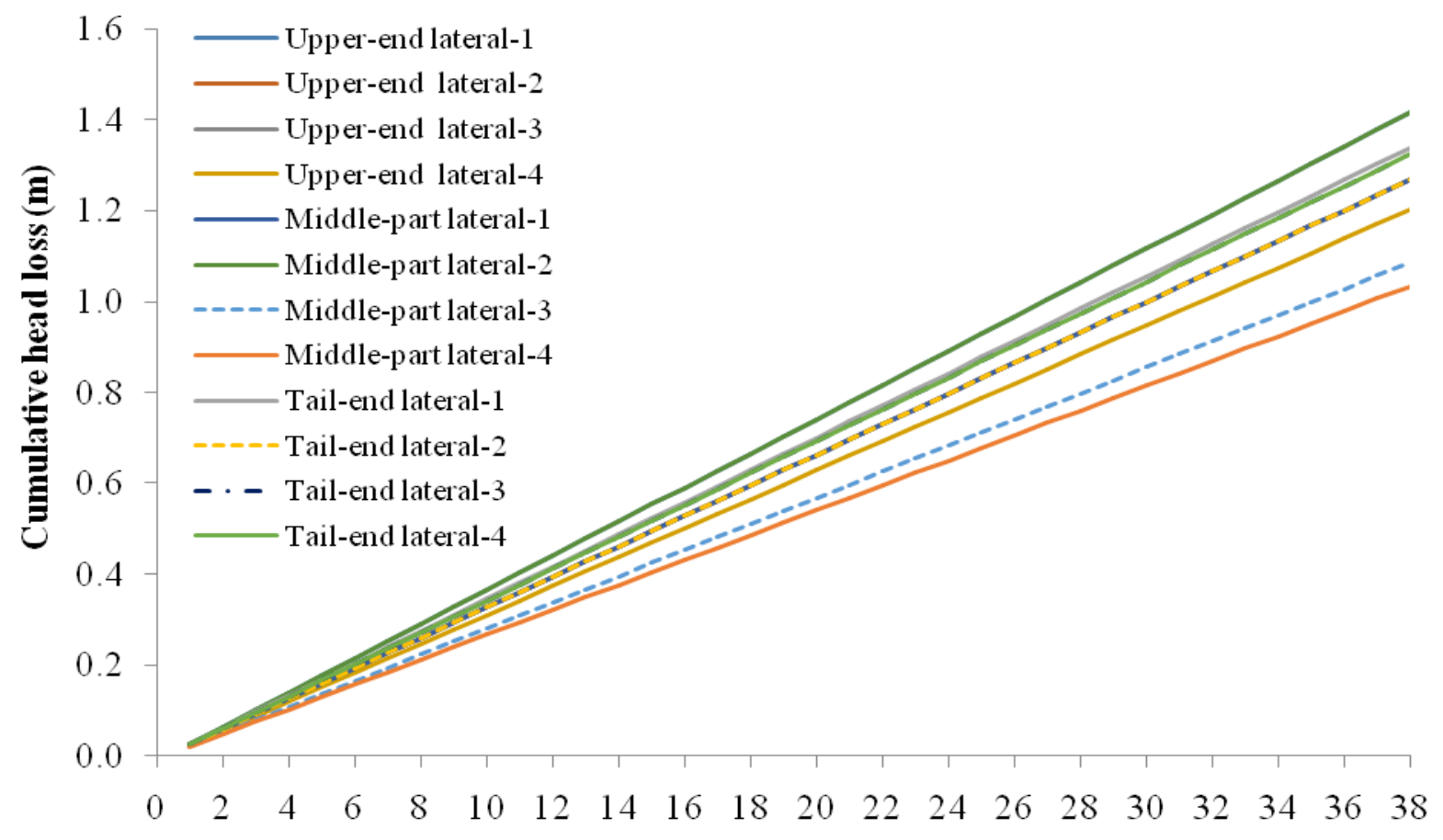

Position of drippers along lateral

Fig.2 Cumulative pressure head loss in the direction of flow along the lateral installed on rightside of sub-main 


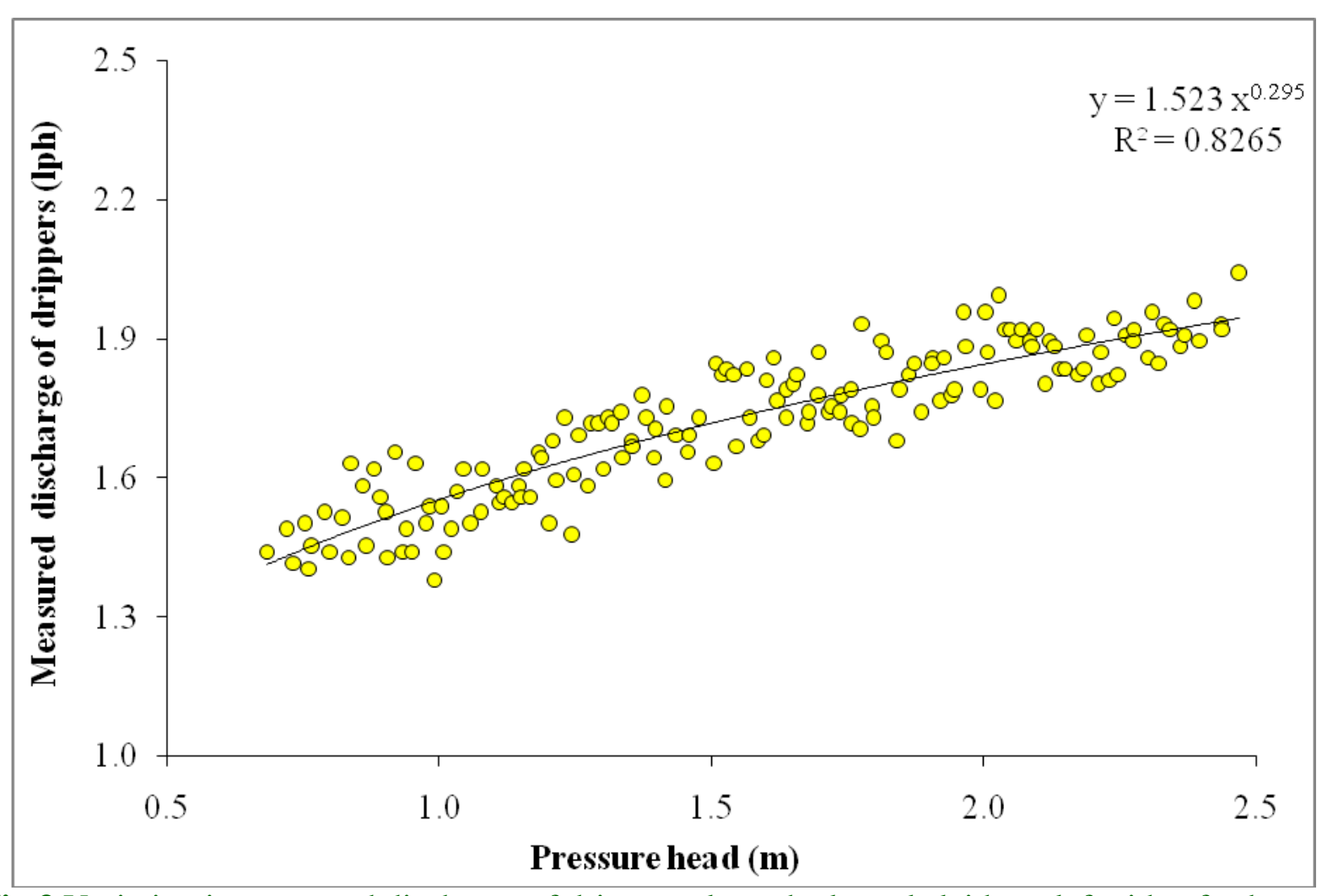

Fig.3 Variation in measured discharge of drippers along the laterals laid out left-side of sub-main installed at experimental field of CAE, Pusa

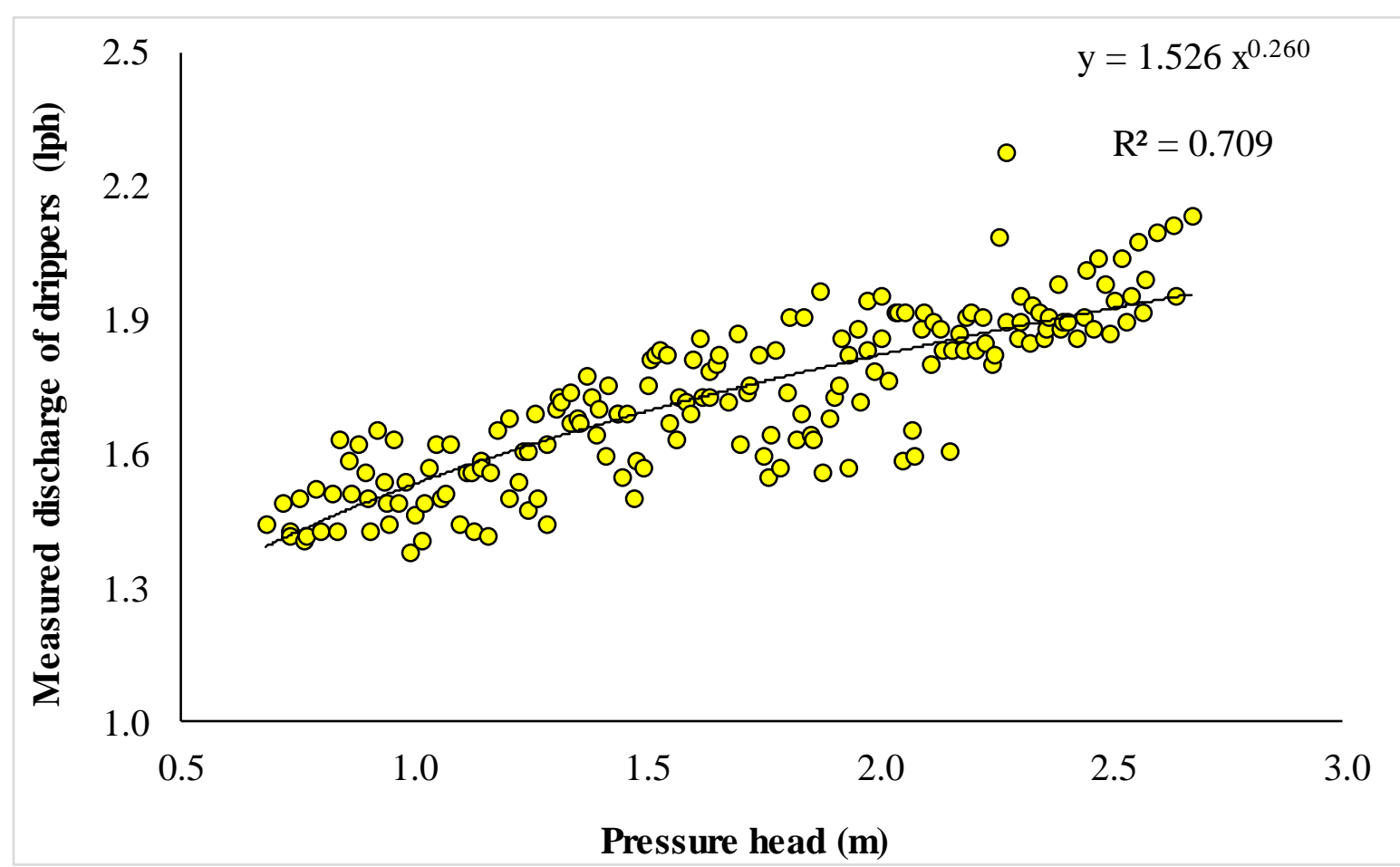

Fig.4 Variation in measured discharge of drippers along the laterals laid outright-side of submain installed at experimental field of CAE, Pusa 
Summary and conclusions are as follows:

The hydraulic characteristics of drippers with drip irrigation system installed at the college premises, variation in dripper's flow rate and pressure head along the laterals were studied. Four laterals on two beds from both sides i.e. left side and right side of the sub-main at upper end, middle part and tail end along the sub-main were selected for evaluation of its performance. Discharge and pressure of selected laterals along the sub-main were measured using volumetric measurent and pressure gauge, respectively. The pressure head varies from $2.0 \mathrm{~m}\left(0.20 \mathrm{~kg} / \mathrm{cm}^{2}\right)$ at tail end to $2.6 \mathrm{~m}\left(0.26 \mathrm{~kg} / \mathrm{cm}^{2}\right)$ at upper end of the sub-main. The mean water flow rate in the lateral was found to be $525 \mathrm{lph}$ in each lateral installed over the field.As per classification criteria, drippers were classified as pressure compensating and the percent variation in water flow rate of drippers was observed to be in the range of 10 to $20 \%$ on the basis of which it can be expressed that the performance of the system may be acceptable. The mean exponent values of 0.31 and coefficient of 1.48 in discharge-pressure relationship of power function for the drip irrigation system was observed for which high value of degree of agreement and lowest value of RMSE and Chi-square test statistics were found.

\section{Acknowledgement}

Authors thankfully acknowledged the College of Agricultural Engineering, Pusa, 848125, Dr.Rajendra Prasad Central Agricultural University, Pusa, Bihar, India.

\section{References}

Badr, A.A., Gomaa, A.H., Amer, K.H.andHasma, A.H. (2009). Design and evaluation of trickle irrigation laterals with single and varying pipe size. Misr. J. of Ag. Eng., 26 (4): 1836: 1854.

Bortolini, L. and Friso, D. (2017). Accuracy of calculation of parameters for characterization of emitters in trickle irrigation. Journal of Irrigation and Drainage Engineering, DOI: 10.1061/(ASCE)IR.19434774.0001233.

Celik, H. K., D. Karayel, M. E. Lupeanu, A. E. W. Rennie and I. Akinci, 2015. Determination of head losses in drip irrigation laterals with cylindrical in- line type dripper $s$ through CFD analysis. Bulg. J. Agric. Sci., 21: 703710.

Giles, R.V., J.B. Evett and C. Liu. (1995). Fluid mechanics and hydraulics: Software and text. In: Schaum's Interactive Outlines, McGraw-Hill Professional Publishing, USA, 384 pp.

Hezarjaribi, A., Dehghani, A.A., Helghi, M. M. and Kiani, A. (2008). Hydraulic Performances of Various Trickle Irrigation Emitters. Journal of Agronomy, 7 (3) : 265 - 271.

Howell, T.A. and Barinas, F.A. (1980). Pressure losses across trickle irrigation fittings and drippers. Transactions of the ASABE, 23 (4) : 928-933.

Keller, J. and Karmeli, D. (1974). Trickle irrigation design parameters. Transactions of the American Society of Agri. Engi.; 17(4):678-684.

Kirnak, H., Dogan, E., Demir, S., and Yalcin, S. (2004). Determination of hydraulic performance of trickle irrigation emitters used in irrigation systems in the Harran Plain, Turkish Journal of Agriculture and Forestry, 28 (4) : 223 230.

López -Urrera, R., Olala, F. M. S., Fabeiro, O., Moratalla, A. (2006). Testing evapotranspiration equations using lysimeter observation in a semiarid climate. Agric. Water Management., 
$85: 15-26$.

Merriam, J.L. and Keller, J. (1978). Farm Irrigation System Evaluation: A Guide for Management. Utah State University.

Mizyed, N. and Kruse, E.G. (2008). Dripper discharge variability of subsurface drip irrigation in uniform soils: Effect on water application uniformity. Trans. of the ASAE; 26:451-458.

Provenzano, G. and Pumo, D. (2004). Experimental analysis of local pressure losses for micro irrigation laterals. Journal of Irrigation and Drainage Engineering, ASCE 130 (4) : 318-324.

Prasad, S., Kumar, V. Sinha, A.K. and Singh,
A.K.P. (2013). Evaluation of Hargreaves method for estimating reference evapotranspiration at Pusa, India. International Agricultural Engineering Journal, 21 (3-4) : 90 - 95.

Soil Conservation Service. (1984). Procedures for Collecting Soil Samples and Methods of Analysis for Soil Survey. USDA-SCS, Soil Survey Investigations Report No. 1. GPO, Washington, DC.

Zhou, L. and Zhou, G. (2009). Measurement and modelling of evapotranspiration over a reed (Phragmites australis) marsh in Northeast China. $J$. Hydrology., 372:41-47.

\section{How to cite this article:}

Aditi Deepak and Sudarshan Prasad. 2020. Evaluation of Hydraulic Performance of Dripper Installed in Drip Irrigation System. Int.J.Curr.Microbiol.App.Sci. 9(06): 3594-3604. doi: https://doi.org/10.20546/ijcmas.2020.906.423 